\title{
Intervenção no uso de estratégias de aprendizagem diante de dificuldades de aprendizagem
}

\author{
Andrea Regina Teixeira \\ Prefeitura Municipal de Cambé - PR \\ Paula Mariza Zedu Alliprandini \\ Universidade Estadual de Londrina - PR
}

\begin{abstract}
Resumo
Este estudo teve como objetivo verificar se a intervenção no uso de estratégias de aprendizagem promove nos alunos com dificuldades de aprendizagem um maior controle e reflexão sobre o seu próprio processo de aprendizagem. Participaram desta pesquisa dez alunos no préteste e pós-teste. A intervenção foi realizada em dezoito encontros de uma hora cada. Foram trabalhados os temas: as estratégias de controle de atenção, do comportamento e ambiente; organização das ideias; seleção e ajustes do tempo; e controle dos pensamentos e de distrações. Para a coleta de dados no pré e pós-teste foi aplicada individualmente uma entrevista estruturada e adaptada por Boruchovitch (1995). Os resultados evidenciam aumento na frequência do uso das estratégias de aprendizagem em sala de aula, no estudo em casa e na realização de tarefas escolares. A intervenção no uso de estratégias de aprendizagem pode contribuir para que os alunos que apresentam dificuldades de aprendizagem possam melhorar o desempenho escolar.
\end{abstract}

Palavras-chave: estratégias de aprendizagem; dificuldades de aprendizagem; intervenção.

\section{Intervention in the use of learning strategies in face of learning difficulties}

\begin{abstract}
This study had the aim to verify if the intervention in the use of learning strategies promotes in students with learning difficulties a greater control and reflection over their own learning process. 10 students participated in the pretest and 10 participated in the post test. The intervention was conducted in 18 sessions of 1 hour each. The strategies on focus were related to attention control, behavior and environment; organization of ideas, selection and adjustments of time, and control of thoughts and distractions. For the pre and post test data collection, a structured interview, adapted by Boruchovitch (1995), was applied. The results show an increase in the frequency of learning strategies use in the classroom, home study and in accomplishing school tasks. The intervention in the use of learning strategies may represent a contribution to students with learning difficulties in helping them improve school performance.
\end{abstract}

Key words: Learning strategies; learning difficulties; intervention.

\section{Interveción en el uso de estrategias de aprendizaje frente a dificultades de aprendizaje}

\footnotetext{
Resumen

Este estudio tuvo como objetivo verificar si la intervención en el uso de estrategias de aprendizaje promueve mejoría en el aprendizaje de los alumnos. Participaron de esta investigación 14 alumnos en el pre-test y 10 en el post-test. La intervención se llevó a cabo en 18 encuentros de 1 hora. Se trabajaron las estrategias de control de atención, del comportamiento y ambiente; organización de ideias, selección y ajustes del tempo, además de control de pensamientos y de distracciones. Para recoger datos pre y post-test se administró individualmente una entrevista estructurada y adaptada por Boruchovitch (1995). Los resultados mostraron un aumento en el número de alumnos que pasan a utilizar las estrategias de aprendizaje en salón de clases, en el estudio en casa y en la realización de tareas escolares. La intervención en el uso de estrategias de aprendizaje puede ayudar a los alumnos que presentan dificultades de aprendizaje a mejorar el rendimiento escolar.

Palabras Clave: Estrategias de aprendizaje; dificultades de aprendizaje; intervención.
} 


\section{Introdução}

A Psicologia Cognitiva, baseada na Teoria do Processamento de Informação, destaca a importância de uma prática pedagógica que leve em consideração o ensino de estratégias cognitivas e metacognitivas, conteúdos processuais e condicionais, juntamente com os conhecimentos declarativos, mais privilegiados pelos professores, tendo em vista a promoção da aprendizagem autorregulada entre os estudantes desde o início da escolarização formal (Boruchovitch, 2004; Dembo, 2000; Hacker, 1998; Hong \& O'neil, 2001; Pozo, 1996; Symons, Snyder, Cariglia-Bull, \& Pressley, 1989; Woolfolk, 2000).

Segundo Boruchovitch (1999), pesquisas têm sugerido que por meio do ensino das estratégias de aprendizagem é possível ajudar os alunos a exercerem maior controle e refletir sobre o seu próprio processo de aprendizagem. Por outro lado, é necessário que o estudante se dedique a estudar. O conhecimento de estratégias de aprendizagem por parte do estudante influencia diretamente o que ele sabe, pode e quer estudar. A autora ressalta ainda que o treinamento em estratégias de aprendizagem tem sido um procedimento bem-sucedido de modo geral, pois é capaz de produzir uma melhora imediata, tanto no uso das estratégias envolvidas quanto no rendimento escolar geral dos alunos. Afirma ainda existirem variáveis que interferem em seu uso, como a ansiedade, a motivação, as crenças sobre inteligência, a autoeficácia, as atribuições de causalidade, depressão infantil e outros fatores.

As estratégias de aprendizagem vêm sendo definidas como sequências de procedimentos ou atividades que se escolhem com o propósito de facilitar a aquisição, o armazenamento e/ou a utilização da informação. Em nível mais específico, pode ser considerado como estratégia de aprendizagem qualquer procedimento adotado para a realização de uma determinada tarefa (Da Silva \& De Sá, 1997).

Pozo (1996), baseando-se na definição de Nisbett, Schucksmith e Dansereau, reafirma que estratégias de aprendizagem são procedimentos e atividades utilizados com o objetivo de facilitar a aquisição, o armazenamento e a utilização da informação. Existem diversas classificações e diferentes tipos de estratégias de aprendizagem; todavia, a literatura vem empregando o termo estratégia de aprendizagem para designar tanto as estratégias de aprendizagem cognitivas quanto as metacognitivas.

Segundo Dembo, citado por Boruchovitch (1999), as estratégias cognitivas são ensaio (repetir, copiar, sublinhar), elaboração (parafrasear, resumir, anotar e criar analogias) e organização (selecionar ideias, usar roteiros e mapas). As estratégias metacognitivas referem-se ao planejamento (estabelecer metas), monitoramento (autotestagem, atenção, compreensão e uso de estratégias) e regulação (ajustar velocidade, reler, rever, uso de estratégias, ajustar ambiente).

Simão (2005) destaca que a aprendizagem escolar encontra-se fortemente dependente do domínio das habilidades de suas estratégias. $\mathrm{O}$ anseio de que essas estratégias sejam inseparáveis do processo de ensinar e aprender exige do professor que saiba combinar o ensino dos conteúdos com as técnicas, os procedimentos e as estratégias, no conjunto de situações concretas que encontra. Dessa maneira, pode-se afirmar que a aprendizagem acontece por um processo cognitivo imbuído de afetividade, relação e motivação.

O fator psicológico tem se revelado tão importante que, nas intervenções em estratégias de aprendizagem, acaba recebendo uma atenção especial. Tem sido sugerido que o ensino de estratégias cognitivas e metacognitivas seja acompanhado pelo ensino de estratégias afetivas, visando acentuar a motivação do aluno e modificar variáveis psicológicas e motivacionais que sejam incompatíveis com o uso eficiente destas estratégias (Boruchovitch, 1994).

Ao se pensar em motivação no contexto escolar, deve-se ter em mente que as atividades ali desenvolvidas possuem muitos diferenciais em relação à motivação em outras áreas, como lazer e esporte. Nas atividades ou tarefas escolares, o aspecto motivacional é responsável por iniciar e manter certos comportamentos, como estudar para garantir uma nota boa na prova, esforçar-se para aprender conteúdos que não têm interesse, entre outros. De fato, o esforço e a persistência em face das dificuldades ou fracassos são úteis para inferir se há ou não motivação, perceber seu nível naquele momento e interferir, se necessário for (Bzuneck, 2001).

Estudos recentes divulgados por diversos pesquisadores confirmam os benefícios de intervenções pedagógicas e psicopedagógicas voltadas para o desenvolvimento cognitivo como forma de se evitar o fracasso escolar (Almeida, 2002; Guthrie, Wigfield, \& Vonsecker, 2000; Pressley \& Woloshyn, 1995; Sadler, 2001; Vauras, Kinnunen, \& Rauhanummi, citado por Boruchovitch, 2004).

Almeida (2002) adverte que o objetivo da intervenção em estratégias de aprendizagem é fazer aumentar o conhecimento do aluno acerca das estratégias de aprendizagem existentes de modo a ajudá-lo a aplicar a melhor estratégia que esteja de acordo com seu estilo. Também afirma que a intervenção em estratégias de aprendizagem deve ampliar o conhecimento dos alunos sobre elas, de modo a assegurar a flexibilidade no seu uso, bem como contribuir para aumentar o autoconhecimento e a autorregulação dos estudantes.

Pressley e cols., citados por Boruchovitch (2007), definiram nove pontos que devem ser levados em conta ao se realizar uma intervenção em estratégias de aprendizagem, que serão brevemente descritos a seguir: ensinar somente uma estratégia de aprendizagem de cada vez, incluindo informações metacognitivas sobre o porquê, o onde e o quando aplicá-la; fornecer explicações pormenorizadas de cada nova estratégia, modelando-a; repetir a modelagem e a explicação, eliminando possíveis dúvidas; criar contextos diversificados, nos quais se possam praticar as estratégias ensinadas; incentivar o monitoramento da compreensão do estudante acerca de como está fazendo e o que está pensando quando está usando as estratégias; prover oportunidades que favoreçam a capacidade do estudante de generalizar o uso das estratégias aprendidas para outras 
situações para as quais elas sejam adequadas; aumentar a motivação dos estudantes e promover o processamento profundo e reflexivo da informação.

Um estudo proposto por Loranger (1994) analisou as estratégias de estudo dos estudantes para determinar se os alunos bem-sucedidos diferiam dos alunos sem êxito na qualidade de seu processamento de informações. O estudo foi baseado no modelo proposto por Pressley, Borkowski e Schneider (1989), o qual sugere que bons processadores de informações usam estratégias para tarefas acadêmicas, como saber como e quando usar essas estratégias. O estudo constatou que, na maior parte do tempo, os alunos bem-sucedidos foram motivados para ter sucesso e usar estratégias para atingir esse objetivo.

Conforme mostra Boruchovitch (1993), alunos com baixo rendimento escolar podem beneficiar-se muito de intervenções em estratégias de aprendizagem. Estes alunos podem aprender a ampliar anotações de aulas, sublinhar partes relevantes de um texto, monitorar a compreensão na hora da leitura, usar técnicas de memorização, fazer resumos, planejar, controlar cognições negativas e estados afetivos motivacionais disfuncionais, entre outras estratégias. Saber utilizar as estratégias de aprendizagem pode se tornar um diferencial nos resultados desses alunos.

Rogers (2010) aponta que, apesar de haver diversas pesquisas que investigam o uso de estratégias de aprendizagem, pouco tem sido escrito sobre o efeito das estratégias de aprendizagem em habilidades produtivas e menos ainda sobre o efeito do treinamento no uso de estratégias metacognitivas e, ainda, sobre como ela deve ser implantada nas salas de aula.

Assim, considerando a importância e necessidade de aprofundamento desta temática, o objetivo da presente pesquisa foi verificar se a intervenção no uso de estratégias de aprendizagem promove nos alunos com dificuldades de aprendizagem um maior controle e reflexão sobre o seu próprio processo de aprendizagem. Como decorrência, a intervenção no uso de estratégias de aprendizagem poderá promover a aprendizagem e possibilitar que esses alunos acompanhem o grupo de alunos em sala de aula, no turno regular.

\section{Método}

\section{Participantes}

Participaram desta pesquisa na situação do pré-teste catorze alunos que frequentavam as aulas de reforço escolar da $4^{\mathrm{a}}$ série do Ensino Fundamental, compreendidos na faixa etária de nove a doze anos. Na situação da intervenção e do pósteste, participaram dez alunos. Para a análise dos dados apresentados neste trabalho, consideram-se apenas os dados dos dez alunos que participaram do pré-teste, da intervenção e do pós-teste, sendo excluídos os dados dos quatro alunos que participaram apenas do pré-teste.

\subsection{Instrumento}

Para a coleta de dados foi aplicada uma entrevista estruturada e adaptada por Boruchovitch (1995), constituída por duas partes: a) dados demográficos da amostra (parte I); b) dados relativos às estratégias de aprendizagem (parte II, questões abertas).

As dezesseis perguntas abertas relativas às estratégias de aprendizagem foram traduzidas e adaptadas de SELF-REGULATED LEARNING INTERVIEW SCHEDULE (Zimmermam Martinez-Pons, citado por Boruchovitch, 1995). Esse instrumento tem como objetivo investigar o uso de estratégias de aprendizagem por parte dos alunos em situações de: a) aprendizagem em sala de aula, b) estudo em casa, c) realização de tarefas escolares em casa. Para maior compreensão dos resultados, as questões que fazem parte do instrumento estão apresentadas a seguir. São elas:

1: "Vamos imaginar que a sua professora esteja dando uma aula de Português e ela avise que vai dar um teste sobre aquela matéria. Você tem alguma maneira que possa ajudá-lo a aprender e a lembrar o que esta sendo dado na aula? Conte para mim o que você faz."

2: "Alguns alunos às vezes percebem que a matéria que a professora está dando é muito difícil e que eles não estão conseguindo entender nada. Isso acontece com você? Você tem alguma maneira que possa ajuda-lo a entender melhor esta matéria tão difícil?"

3: "Vamos imaginar que a sua professora the peça que escreva uma redação ou texto sobre sua família, sobre o que você fez no final de semana ou sobre as coisas de que você gosta. A professora lhe avisa que a redação vai valer nota. Você tem alguma maneira ou método que possa ajudá-lo a planejar e a escrever melhor a sua redação? O que é que você faz?"

4: "Vamos imaginar que a sua professora lhe passe um dever de casa de Matemática que você terá de fazer sem a ajuda dela. Você tem alguma maneira ou método que possa ajudá-lo a fazer esse dever de forma certa? O que é que você faz?".

5: "A maioria dos professores costuma dar provas que valem nota ou conceito. As suas notas ou conceitos são usados para decidir se você vai ou não passar de ano. Você tem alguma maneira que possa ajudá-lo a se preparar, por exemplo, para a sua prova de Português? O que é que você faz?".

6: "Às vezes você precisa decorar alguma informação para se sair bem na prova. Você tem alguma maneira que possa ajudá-lo a se lembrar melhor? Conte para mim o que você faz."

7: "Quando você está estudando para uma prova e percebe que não vai haver tempo para você aprender tudo que precisa para se sair bem no dia seguinte, o que você faz?".

8: "Quando você está fazendo uma prova e percebe que realmente não sabe como responder algumas questões, o que é que você faz?". 
9: "Você costuma fazer alguma coisa com as questões que você errou? O que é que você faz?".

10: "Muitas vezes os alunos não fazem seus deveres de casa porque há uma porção de outras coisas que eles gostariam de fazer, como jogar bola, assistir televisão, brincar com os amigos. Isso acontece com você?".

11: "Muitas vezes os alunos acham que aquilo que estão estudando é muito chato. Isso acontece com você? Você tem alguma maneira de fazer aquela matéria que está desinteressante ficar mais agradável? O que é que você faz?".

12: "Quando você está estudando, onde você costuma ficar? Por que você escolhe este lugar?".

13: "Quando você acaba de fazer um dever de casa, você faz alguma coisa para ver se fez o dever de maneira correta? O que é que você faz?".

14: "Quando está fazendo uma prova de Português ou Matemática, você faz alguma coisa para ter certeza de que suas respostas estejam corretas antes de entregar a prova ao professor? O que é que você faz?".

15:"Alguns alunos às vezes percebem que não conseguem entender nada ou quase nada do que estão lendo. Isso acontece com você? O que você costuma fazer para ajudar a entender melhor aquilo que você está lendo?".

16: "Alguns alunos às vezes percebem que, quando a professora está falando, eles estão pensando em outra coisa e não sabem o que ela está falando. O que você costuma fazer para ajudá-lo a prestar atenção ao que a professora está falando?"

\subsection{Procedimento}

Inicialmente foi solicitada a autorização da diretoria da escola para desenvolver o presente trabalho, e, mediante a assinatura do Termo de Consentimento Livre e Esclarecido (TCLE) pelos pais ou responsáveis, o presente trabalho foi iniciado, atendendo a todos os procedimentos éticos estabelecidos pela Resolução do CNS 196/96.

O presente trabalho foi constituído de três momentos: o primeiro foi a aplicação do instrumento, considerado como pré-teste; no segundo foi realizada a intervenção; e no terceiro momento foi reaplicado o mesmo instrumento, considerado como pós-teste.

A partir dos dados obtidos, na situação do pré-teste foram trabalhadas as estratégias de: controle da atenção, do comportamento e do ambiente; organização mental das ideias; seleção e ajustes em função do tempo; controle dos pensamentos e de distrações, momento considerado como intervenção. A proposta foi trabalhar com textos já utilizados pela professora na sala regular, relendo, interpretando e produzindo histórias a partir deles, buscando desenvolver as estratégias anteriormente citadas.

O processo de intervenção foi desenvolvido no período de nove semanas, durante o qual eram realizados dois encontros semanais, no contraturno, totalizando dezoito encontros, com duração de uma hora cada um.
Nos seis primeiros encontros foram trabalhados os seguintes textos: "Os doze trabalhos de Hércules" de Monteiro Lobato, "A Mosca" de Neil Philip, "A Aposta" de Luciana M. M. Passos, "A Velha e os Ladrões" de Isabel Solé. Durante os encontros foram trabalhadas as estratégias de aprendizagem cognitivas (sublinhar, anotar, escrever, revisar, reescrever, conferir, pedir ajuda, reler cuidadosamente, corrigir por iniciativa própria, associações com o lúdico, entre outras). Do $7^{\circ}$ ao $12^{\circ}$ encontro foi incluído, durante as atividades, o uso de estratégias metacognitivas como: por que, onde e quando aplicá-las; fornecer explicações pormenorizadas de cada nova estratégia, modelando-a; repetir a modelagem e a explicação, eliminando possíveis dúvidas; criar contextos diversificados, nos quais se pudessem praticar as estratégias ensinadas; incentivar o monitoramento da compreensão do aluno acerca de como está fazendo e o que está pensando quando está usando as estratégias; promover oportunidades que favoreçam a capacidade do aluno de generalizar o uso das estratégias aprendidas para outras situações nas quais elas sejam adequadas; aumentar a motivação dos estudantes e promover o processamento profundo e reflexivo da informação. Nestes encontros foram trabalhados os seguintes textos: H1N1, Cão, Cão, Cão, de Millôr Fernandes; Sistema Monetário Brasileiro; desenhos para produção de texto e histórias da Turma do Sítio do Pica-pau Amarelo, de Monteiro Lobato.

Durante os seis últimos encontros o trabalho foi realizado de forma a abranger as seguintes estratégias: 1) ensaio, que envolve repetir ativamente, tanto pela fala como pela escrita, o material a ser aprendido; 2) elaboração de estratégias, que implicou a realização de conexões entre o material novo a ser aprendido e o material antigo e familiar (por exemplo, reescrever, resumir, criar analogias, tomar notas que vão além da simples repetição, criar e responder perguntas sobre o material a ser aprendido); 3) organização, que se referiu à imposição de estrutura ao material a ser aprendido; 4) monitoramento da compreensão, que implicou que o aluno estivesse constantemente com a consciência realista de quanto ele estava sendo capaz de captar e absorver do conteúdo que estava sendo ensinado (por exemplo, tomar alguma providência quando se percebia que não entendeu, autoquestionamento para investigar se houve compreensão, usar os objetivos a serem aprendidos como uma forma de guia de estudo, estabelecer metas e acompanhar o progresso em direção à realização dos mesmos, modificar estratégias utilizadas, se necessário); e 4) as estratégias afetivas, que se referiram à eliminação de sentimentos desagradáveis, que não condiziam com a aprendizagem (por exemplo, estabelecimento e manutenção da motivação, manutenção da atenção e concentração, controle da ansiedade, planejamento apropriado do tempo e do desempenho).

Para essas estratégias de aprendizagem foram utilizados os textos "Os Bichos da Minha Casa", de Clarice Lispector, e "Três Pescadores" (notícia de revista) além de desenhos para construção de texto e sequências de desenhos para elaboração de frases. 
Ao final, o mesmo instrumento utilizado na situação de pré-teste foi reaplicado, de forma a atender ao objetivo proposto no presente trabalho.

\section{Resultados e discussões}

Inicialmente, a partir das respostas apresentadas pelos participantes na aplicação do instrumento, tanto na situação de pré quanto na de pós-teste, foram criadas as categorias de resposta relacionadas às estratégias de aprendizagem. Na sequência, as categorias de respostas apresentadas foram tabuladas e transformadas em frequência e porcentagem. A tabela 1, apresentada a seguir, descreve as frequências e porcentagens obtidas a partir das categorias de respostas apresentadas pelos alunos pesquisados na situação de pré e pós-teste em relação a cada pergunta do instrumento aplicado.
Ao analisar os resultados relativos às questões 1,2 , $3,5,12,15$ e 16, apresentados na tabela 1, é possível observar que, na situação do pré-teste, poucos alunos (entre 10\% e $30 \%$ ) relataram prestar atenção às situações de estudo em sala de aula, à compreensão de conteúdo, à escrita de uma redação, à preparação para testes e à organização do ambiente de estudo, e a maioria (entre $40 \%$ a $50 \%$ ) respondeu que não faz nada nesses momentos, não se prepara, ou não sabe o que faz, deixando claro que, além de não utilizarem as estratégias de aprendizagem, não possuem motivação suficiente para se dedicar aos estudos. Na situação do pós-teste, o nível de atenção dos alunos variou entre $10 \%$ a $50 \%$, em especial no contexto de sala de aula, mas também na organização do ambiente de estudo, ao evitar distrações (50\%). Estes resultados permitem inferir que a intervenção desenvolvida com estes alunos possibilitou um maior controle e reflexão sobre o processo de aprendizagem.

Tabela 1. Questões, categorias de resposta, frequência e porcentagem de respostas de alunos nas situações de pré e pós-teste.

\begin{tabular}{|c|c|c|c|c|c|}
\hline \multirow[t]{2}{*}{ Questões } & \multirow[t]{2}{*}{ Categorias } & \multicolumn{2}{|c|}{ Pré-teste } & \multicolumn{2}{|c|}{ Pós-teste } \\
\hline & & Freq. & $\%$ & Freq. & $\%$ \\
\hline \multirow[t]{5}{*}{ 1. Aprendizagem em sala de aula } & Prestar atenção & 2 & 20 & 4 & 40 \\
\hline & Perguntar para a professora & 1 & 10 & 0 & 0 \\
\hline & Ler & 2 & 20 & 1 & 10 \\
\hline & Estudar a matéria/decorar & 1 & 10 & 5 & 50 \\
\hline & Não sei/nada & 4 & 40 & 0 & 0 \\
\hline \multirow[t]{4}{*}{ 2. Compreensão do conteúdo } & Pedir ajuda/perguntar & 3 & 30 & 7 & 70 \\
\hline & Prestar atenção & 1 & 10 & 0 & 0 \\
\hline & Ler & 1 & 10 & 2 & 20 \\
\hline & Nada & 5 & 50 & 1 & 10 \\
\hline \multirow[t]{7}{*}{ 3. Redação } & Pedir ajuda & -- & -- & 2 & 20 \\
\hline & Escrever & 1 & 10 & 1 & 10 \\
\hline & Organizar o pensamento & 2 & 20 & 3 & 30 \\
\hline & $\begin{array}{l}\text { Preocupações estética/ } \\
\text { gramática }\end{array}$ & 1 & 10 & 0 & 0 \\
\hline & Prestar atenção & 1 & 10 & 2 & 20 \\
\hline & Planejar a atividade & 0 & 0 & 2 & 20 \\
\hline & Não sei/nada & 5 & 50 & 0 & 0 \\
\hline \multirow[t]{4}{*}{ 4. Dever de casa de matemática } & Conferir & 2 & 20 & 2 & 20 \\
\hline & Resolver & 0 & 0 & 1 & 10 \\
\hline & Pedir ajuda & 4 & 40 & 7 & 70 \\
\hline & Não sei/nada & 4 & 40 & 0 & 0 \\
\hline \multirow[t]{5}{*}{ 5. Preparação para os testes } & Decorar a matéria & 1 & 10 & 3 & 30 \\
\hline & Estudar bastante/Ler & 4 & 40 & 6 & 60 \\
\hline & Copiar a matéria & 0 & 0 & 1 & 10 \\
\hline & Prestar atenção & 1 & 10 & 0 & 0 \\
\hline & Não sei/nada & 4 & 40 & 0 & 0 \\
\hline
\end{tabular}


(continuação)

\begin{tabular}{|c|c|c|c|c|c|}
\hline \multirow[t]{3}{*}{ 6. Decorar } & Decorar & 4 & 40 & 6 & 60 \\
\hline & Estudar & 2 & 20 & 4 & 40 \\
\hline & Não sei/nada & 4 & 40 & 0 & 0 \\
\hline \multirow[t]{4}{*}{ 7. Administração de tempo } & Não se prepara para a prova & 5 & 50 & 0 & 0 \\
\hline & Selecionar/ajustar o tempo & 1 & 10 & 1 & 10 \\
\hline & Comportamento inalterado & 2 & 20 & 5 & 50 \\
\hline & Pedir ajuda a para a professora & 2 & 20 & 4 & 40 \\
\hline \multirow[t]{5}{*}{ 8. Resolução de problemas } & Pedir ajuda ao professor & 1 & 10 & 3 & 30 \\
\hline & Deixar em branco & 5 & 50 & 3 & 30 \\
\hline & Chutar & 3 & 30 & 1 & 10 \\
\hline & Deixar por último para resolver & 0 & 0 & 2 & 20 \\
\hline & Não sei/nada & 1 & 10 & 1 & 10 \\
\hline \multirow[t]{3}{*}{ 9. Correção de questões erradas } & Fazer a correção & 0 & 0 & 7 & 70 \\
\hline & Alterar comportamento & 4 & 40 & 0 & 0 \\
\hline & Não sei/Nada & 6 & 60 & 3 & 30 \\
\hline \multirow[t]{2}{*}{ 10. Motivação para o dever de casa } & Sim & 6 & 60 & 7 & 70 \\
\hline & Não & 4 & 40 & 3 & 30 \\
\hline \multirow{3}{*}{$\begin{array}{l}\text { 11. Motivação para estudar matéria } \\
\text { desinteressante }\end{array}$} & Associar com o Lúdico & 1 & 10 & 1 & 10 \\
\hline & Concentrar/calma & 1 & 10 & 1 & 10 \\
\hline & Não sei/Nada & 8 & 80 & 8 & 80 \\
\hline \multirow{4}{*}{$\begin{array}{l}\text { 12. Organização do Ambiente de } \\
\text { estudo }\end{array}$} & Condições físicas & 2 & 20 & 2 & 20 \\
\hline & Evitar distrações & 2 & 20 & 5 & 50 \\
\hline & Presença de distrações & 2 & 20 & 0 & 0 \\
\hline & Relação com ooutro & 4 & 40 & 3 & 30 \\
\hline \multirow{3}{*}{$\begin{array}{l}\text { 13. Auto-avaliação da realização do } \\
\text { dever de casa }\end{array}$} & Pedir ajuda & 2 & 20 & 4 & 40 \\
\hline & Conferir sozinho & 2 & 20 & 5 & 50 \\
\hline & Nada & 6 & 60 & 1 & 10 \\
\hline \multirow{2}{*}{$\begin{array}{l}\text { 14. Conferência da prova de } \\
\text { português ou matemática }\end{array}$} & Revisar & 7 & 70 & 10 & 100 \\
\hline & Não sei/nada & 3 & 30 & 0 & 0 \\
\hline \multirow[t]{4}{*}{ 15. Dificuldades na leitura } & Pedir ajuda & 2 & 20 & 4 & 40 \\
\hline & Prestar atenção & 1 & 10 & 1 & 10 \\
\hline & Reler cuidadosamente & 4 & 40 & 5 & 50 \\
\hline & Nada & 3 & 30 & 0 & 0 \\
\hline \multirow[t]{5}{*}{ 16. Prestar atenção professora } & Evitar distrações & 3 & 30 & 4 & 40 \\
\hline & Controlar do pensamento & 1 & 10 & 1 & 10 \\
\hline & Concentrar no professor & 3 & 30 & 2 & 20 \\
\hline & Não sei/nada & 3 & 30 & 1 & 10 \\
\hline & Ficar quieto & 0 & 0 & 2 & 20 \\
\hline
\end{tabular}

Quanto à motivação do aluno para aprender, Leite, Ruiz, Ruiz, Aguiar e Oliveira (2005) ressaltam que a motivação é, e sempre será, uma grande aliada na aprendizagem, pois sem motivação o processo de aprendizagem perde o seu significado. Para Sisto, Boruchovitch, Fini, Brenelli \& Martinelli (2001), a motivação está diretamente ligada à aprendizagem; é a iniciação e manutenção de comportamento com o objetivo de atingir uma meta. Os dados apresentados mostram inicialmente um número acentuado de alunos não usa estratégias de aprendizagem, evidenciando uma desmotivação em desenvolver habilidades e estratégias para a aprendizagem e a necessidade de que o professor conheça melhor os fatores que influenciam a motivação em sala de aula e busquem formas para promovê-la.

Com relação a perguntar/pedir ajuda ao professor apresentado nos resultados das questões 1, 2, 3, 4, 7, 8, 13 e 15 na situação do pré-teste, os resultados evidenciam uma frequência entre $10 \%$ e $40 \%$, o que deixa explícita a 
dificuldade dos alunos participantes em pedir ajuda ao professor, e talvez até uma falta de interação entre eles. Após a intervenção, a frequência do uso dessa estratégia ficou entre $20 \%$ e $70 \%$, evidenciando que alguns alunos que antes não utilizavam esta estratégia passam a utilizá-la em algumas situações. Costa (2000), baseado nos estudos de Barnett, Darcie, Holland e Kobasegawa (1982), Nelson Le Gall e Gumerman (1984) e Newman (1990), ressalta que procurar ajuda, além de ser mais uma estratégia no repertório do aluno, envolve também o processo de interação social que acontece em sala. As crianças frequentemente temem a reação dos professores e colegas, principalmente quando o esperado é que elas saibam como resolver a questão sem ajuda adicional. Segundo Costa (2000), procurar ajuda é considerado como uma das mais importantes estratégias existentes, pois possibilita que o aluno aprenda outras habilidades. A criança que pergunta e obtém assistência quando é necessária, além de resolver suas dificuldades acadêmicas, adquire conhecimentos e habilidades que poderão ajudá-la futuramente. Destarte, passar a utilizar esta estratégia de pedir ajuda pode ter favorecido uma maior interação dos alunos no contexto de sala de aula e ter ajudado na resolução de suas dificuldades acadêmicas.

Ribeiro (2003), baseado nos estudos de Brown, ressalta que reconhecer a dificuldade na compreensão de uma tarefa, ou tornar-se consciente de que não se compreendeu algo, é uma habilidade que parece distinguir os bons dos maus leitores. Os primeiros sabem avaliar as suas dificuldades e/ou falta de conhecimento, o que lhes permite, nomeadamente, superá-las, recorrendo, muitas vezes, a inferências feitas a partir daquilo que sabem. Esta autora chama, assim, a atenção para a importância do conhecimento, não só sobre aquilo que se sabe, mas também sobre aquilo que não se sabe, evitando assim o que designa de ignorância secundária: não saber que não se sabe.

Quando os alunos que respondem no pré-teste (questões 13, 14 e 15) fazem uma releitura do assunto em questão (entre $20 \%$ a $70 \%$ ), deixam explícita a utilização da estratégia de repetição, que, segundo Boruchovitch (2007), é usada para reter a informação por um período de tempo mais longo. Repetir ou ensaiar a informação que está na memória de curta duração são exemplos de algumas estratégias que as pessoas usam para reter melhor a informação. Algumas destas estratégias são automáticas e inconscientes. A repetição (ensaio) não é ensinada de forma estruturada em sala de aula, mas é adquirida espontaneamente já no início da educação escolar. No pós-teste, os resultados indicam um aumento na frequência do uso desta estratégia ( $50 \%$ a $100 \%)$, sendo que agora eles o fazem de maneira consciente, o que pode trazer benefícios para o processo de aprendizagem.

Ribeiro (2003), baseado nos estudos de Flavell e Wellman, ressalta que, para a memorização ou a recordação se tornarem possíveis, o sujeito deve aprender a identificar em que situações há necessidade de recorrer a determinadas ações ou estratégias (sensibilidade) e desenvolver o conhecimento sobre a influência das variáveis que envolvem esse processo. Assim, se for devidamente utilizada, esta estratégia poderá trazer êxito para esses alunos. Os resultados apresentados pelos alunos neste trabalho, em relação às categorias de estudar/decorar a matéria nas questões 1 , 5 e 6, variaram entre $10 \%$ a $40 \%$, o que mostra falta de interesse desses alunos com relação aos estudos, pois não são capazes de reler a matéria. Na situação de pós-teste esse número variou entre $30 \%$ e $60 \%$, evidenciando um aumento no uso desta estratégia após a intervenção.

Segundo Costa (2000), pesquisas realizadas (Britton \& Tesser, por exemplo) para examinar a administração de tempo de estudantes mostram que o planejamento de longa extensão, utilizado por alunos que planejam seu tempo com bastante antecedência como metas para o trimestre, conseguem obter maior desempenho acadêmico. Esses resultados mostram implicações positivas, pois manejar o tempo de forma adequada é uma meta que pode ser ensinada. Alunos que praticam a administração de tempo têm maior clareza sobre a estruturação do tempo e possuem melhor desempenho escolar. Os dados obtidos na questão 7, quando comparados os resultados na situação de pré em relação ao pós-teste, evidenciam a necessidade de que o uso desta estratégia seja mais bem trabalhada, de forma a promover um melhor desempenho escolar.

A questão 12 trata da organização do ambiente, e as respostas mostram que $20 \%$ das crianças no pré-teste escolhem para a realização das atividades de estudo locais mais calmos sem presença de coisas que provoquem distração, sendo que no pós-teste esse número aumenta para $50 \%$. Costa (2000) relata que uma investigação realizada por Patton, Stinard e Routh e Mercuri sobre as condições do local de estudo que mais agradam aos estudantes revelou que essas variam conforme o tipo de tarefa (somente ler, ler e escrever, escrever e matemática). Locais calmos são escolhidos quando a atividade envolve somente leitura.

Idealmente, os professores funcionam como mediadores da aprendizagem e agem como promotores da autorregulação, ao possibilitarem a emergência de planos pessoais. De acordo com Brown, citado por Ribeiro (2003), eles assumem um papel fundamental na preparação dos alunos para planejar e monitorar as suas próprias atividades. Para estimular a metacognição, o professor tem toda a vantagem de multiplicar as situações abertas de investigação, resolver problemas complexos nos quais o sujeito deva escolher entre várias alternativas e antecipar as consequências destas escolhas. Só este gênero de atividade pode dar ao aluno, sobretudo se tem dificuldades, a oportunidade de conduzir de maneira refletida as suas próprias operações cognitivas (Grangeat, citado por Ribeiro, 2003).

O fato de as estratégias de aprendizagem terem sido cuidadosamente detalhadas em função da especificidade das situações propostas no pré-teste fez surgir uma quantidade expressiva de estratégias de aprendizagem (controlar a atenção, o comportamento e o ambiente; procurar assistência social; ler e escrever mecanicamente; organizar mentalmente as ideias; preocupar-se com a estética, a técnica e a gramática; conferir/checar; ler; selecionar e fazer ajustes em função do tempo; comportar-se de forma inalterada; 
"chutar"; corrigir por iniciativa própria; fazer associações com o lúdico; evitar distrações; distrair-se com coisas; conferir várias vezes a prova; pedir ao professor que a confira; reler cuidadosamente; controlar os pensamentos; concentrar-se na figura e na postura do professor). Não obstante, convém destacar que, apesar de terem relatado um total de 19 estratégias de aprendizagem, os alunos mencionraam utilizá-las pouco frequentemente, de modo que muitas vezes as utilizavam sem saber como deveriam fazê-lo de maneira eficaz.

De acordo com os dados apresentados, após a intervenção as crianças começaram a prestar mais atenção à explicação da professora, aumentando a porcentagem de $10 \%$, no pré-teste, para $40 \%$ no pós-teste. Também começaram a estudar novamente a matéria dada, para aprender em sala de aula (o nível aumentou de $10 \%$ a $40 \%$ no pré-teste para $30 \%$ a $60 \%$ no pós-teste), com o diferencial de que agora elas já sabem que estão utilizando uma estratégia que as ajudará na aprendizagem.

Quanto à compreensão do conteúdo, houve um aumento no número de crianças (de $20 \%$ para $70 \%$ ) que revelaram pedir ajuda. A estratégia de pedir ajuda torna a criança mais ativa e disposta para o aprendizado.

O nível de atenção na hora de escrever uma redação aumentou (de $10 \%$ para $20 \%$ ), com a diferença de que agora as crianças planejam a atividade a ser realizada.

$\mathrm{Na}$ hora do dever de casa, as crianças se mostraram mais ativas (de $40 \%$ para $70 \%$ ), pois pedir ajuda envolve iniciativa e demonstra mais segurança, porque muitas vezes as crianças não pedem ajuda por sentir vergonha de não saber resolver as atividades propostas.

No tocante à correção das questões erradas da prova, a maioria das crianças relata fazer a correção (70\%) no pós- teste, o que não aconteceu no resultado da aplicação do instrumento no pré-teste (10\%). Corrigir as questões erradas da prova também é uma forma de aprendizado.

O nível de preparação para testes aumentou significativamente (de $10 \%$ para $60 \%$ ); agora as crianças sabem que, se estudarem corretamente, conseguirão se sair bem nos testes e provas.

Antes do processo de intervenção, as crianças disseram que decoravam a matéria (entre $10 \%$ e $40 \%$ ), porém não sabiam o significado; agora elas reafirmam que decoram a matéria (de $40 \%$ a $60 \%$ ), porém com o conhecimento sobre ela, além de afirmarem que a estudavam (40\%). Ainda em relação ao item decorar, no pré-teste $40 \%$ das crianças relatam que não faziam nada, e no pós-teste esta porcentagem caiu para $0 \%$, sendo que $40 \%$ relataram que estudavam e $60 \%$ que decoravam, o que evidencia que alguns alunos passaram a usar estas estratégias de aprendizagem que antes não utilizavam.

A instrução no uso de estratégias de aprendizagem procurou assegurar um ensino progressivo e adequado à série e à idade dos alunos. Em todos os encontros, além de se ensinarem as estratégias de planejamento, leitura e produção de textos (ensino explícito e autorregulação), os aspectos motivacionais e afetivos também foram trabalha- dos, como recomenda a literatura da área à luz da Psicologia Cognitiva, com base na Teoria do Processamento da Informação. Este encaminhamento baseou-se na proposta de Costa e Boruchovitch (2009), que indicam que o principal objetivo das estratégias de aprendizagem é ensinar a pensar. O que se quer é educar o aprendiz para obter autonomia, independência e senso crítico. Assim, a estratégia deve ser dinâmica e sofrer constantes reavaliações, além de, no momento exato da sua aplicação, ser observada e reestruturada quando necessário.

De forma geral, os dados do pré-teste desta pesquisa possibilitaram observar que muitas vezes os alunos utilizam as estratégias de aprendizagem sem saber que as estão utilizando. Como citado anteriormente, essas crianças procuram locais mais tranquilos para estudar, muitas vezes releem a matéria e a decoram, mas não fazem isto como uma forma de estratégia, pois relatam também que muitas vezes não sabem o que fazer em determinadas situações de estudo em sala de aula. Se soubessem realmente utilizar as estratégias de aprendizagem, não ficariam sem saber o que fazer em momentos de preparação para testes ou em situações de estudo em sala de aula. Assim, a utilização ineficaz das estratégias de aprendizagem não produz efeito positivo na aprendizagem.

Os alunos, de forma geral, não se questionam nem refletem sobre o que fazer para aprender mais e melhor. Isso acontece porque a aprendizagem ocorre de forma automática e muitas vezes os fatores subjacentes ao processo da boa aprendizagem passam despercebidos, porém a consciência dos elementos que interferem na aprendizagem eficiente só emerge quando o aluno assume um comportamento intencional para conseguir êxito (Da Silva e De Sá, citado por Rios, 2006).

Assim as estratégias de aprendizagem devem ser entendidas não somente como uma forma de conduta de estudo, mas também como um processo de autoconhecimento a respeito de si mesmo e de próprias capacidades.

Ensinar o uso de estratégias de aprendizagem para alunos com dificuldades de aprendizagem é de extrema relevância, pois interfere diretamente na autoestima deles. Quando o aluno melhora o seu desempenho escolar, passa a acreditar em suas potencialidades e, dessa forma, passa a desenvolvê-las.

Apesar de a instrução em estratégias de aprendizagem ser uma área relativamente nova, com metodologias diversas, ela pode oferecer importantes contribuições para a educação: primeiramente, porque a instrução em estratégias de aprendizagem relaciona e esclarece a inter-relação entre elementos cognitivos, motivacionais e afetivos presentes no processo e nos resultados da aprendizagem (Da Silva \& De SÁ, 1997); além disso, demonstra que é possível, no âmbito escolar, ensinar ao estudante como aprender de forma mais eficiente e ter mais controle sobre sua motivação e suas emoções, aumentando a confiança na própria capacidade cognitiva e potencializando o seu rendimento acadêmico. 


\section{Considerações finais}

Em linhas gerais, os resultados apresentados pelos alunos após a intervenção no uso de estratégias de aprendizagem evidenciam que o objetivo foi atingido, uma vez que os alunos pesquisados que apresentavam dificuldades de aprendizagem passaram a ter um maior controle e reflexão sobre o seu próprio processo de aprendizagem. As crianças começaram a prestar mais atenção à explicação da professora, estudar a matéria dada novamente e até decorar a matéria para que a aprendizagem em sala de aula ocorresse. O mesmo pode ser inferido quanto à compreensão do conteúdo e preparação para testes. Os resultados da presente pesquisa indicam que a intervenção em estratégias de aprendizagem fornece subsídios para que o aluno se torne mais ativo para o aprendizado, no que diz respeito não apenas às estratégias cognitivas, mas também às estratégias metacognitivas.

Assim como os autores anteriormente citados, ressalta-se a necessidade de o professor compreender melhor os processos cognitivos de seus alunos, bem como a importância de ensinar os alunos a usar de maneira efetiva e eficiente as estratégias de aprendizagem, fatores que podem levar à promoção de uma aprendizagem mais dinâmica e significativa para seus alunos.

\section{Referências}

Almeida, L. S. (2002). Facilitar a aprendizagem: ajudar os alunos a aprender e a pensar. Psicologia Escolar e Educacional, 6(2), 155165.

Boruchovitch, E. (1993). A psicologia cognitiva e a metacognição: novas perspectivas para o fracasso escolar brasileiro. Tecnologia Educacional, 22, 22-28.

Boruchovitch, E. (1994). As variáveis psicológicas e o processo de aprendizagem: uma contribuição para a psicologia escolar. Psicologia: Teoria e Pesquisa, 10(1), 129-139.

Boruchovitch, E. (1995). A identificação e o estudo das variáveis associadas ao fracasso escolar brasileiro. Projeto de pesquisa realizado na qualidade de bolsista de recém-doutor do CNPq, Faculdade de Educação, Departamento de Psicologia Educacional. Universidade de Campinas-SP.

Boruchovitch, E. (1999). Estratégias de aprendizagem e desempenho escolar: considerações para a prática educacional. Psicologia: Reflexão e Crítica, 12(2), 361-376.

Boruchovitch, E. (2007). Aprender a Aprender: Propostas de intervenção em estratégias de aprendizagem. Educação Temática Digital, 8(2), 156-167.

Boruchovitch, E. (2004). A auto-regulação da aprendizagem e a escolarização inicial. Em E. Boruchovitch, J. A. Bzuneck (Orgs.),
Aprendizagem: processos psicológicos e o contexto social na escola (pp. 55-88). Petrópolis, RJ: Vozes.

Bzuneck, J. A. (2001). A motivação do aluno: Aspectos introdutórios. Em E. Boruchovitch \& J. A. Bzuneck (Orgs.). Motivação do aluno: Contribuições da psicologia contemporânea (pp. 9-36). Petrópolis, RJ: Vozes.

Britton, B. K., \& Tesser, A. (1991). Effects of time management practices of college grades. Journal of Educational Psychology, $83,405-410$.

Costa, E. R. (2000). As estratégias de aprendizagem e a ansiedade de alunos do ensino fundamental: Implicações para a prática educacional. Dissertação de Mestrado em Educação, Curso de Pós-Graduação em Psicologia Educacional, Universidade Estadual de Campinas. Campinas-SP.

Costa, E. R. \& Boruchovitch, E. (2009). As estratégias de aprendizagem e a produção de textos narrativos. Psicol. Reflex. Crit. [online], 22 (2), 173-180.

Da Silva A. L. \& De Sá, L. (2007). Saber estudar e estudar para saber. Porto, Portugal: Porto Editora.

Leite, E. C. R., Ruiz, J. B., Ruiz, A. M. C., Aguiar, T. F., \& Oliveira. M. R. C. (2005). Influência da Motivação no Processo EnsinoAprendizagem. Akrópolis, 13(1), 23-29.

Loranger, A. L. (1994). The study of successful and unsuccessful high school students. Journal of Reading Behavior, 26(4), 347-360.

Pressley, M., Borkowski, J. G., \& Schneider, W. (1989). Good information processing: What it is and how education can promote it. Journal of Educational Research, 13(8), 857-867.

Pozo, J. J. (1996). Estratégias de Aprendizagem. Em C. Coll, J. Palácios \& A. Marchesi (Orgs), Desenvolvimento psicológico e educação: Psicologia da educação (pp. 176-197). Porto Alegre: Artes Médicas.

Ribeiro, C. (2003). Metacognição: Um Apoio ao Processo de Aprendizagem. Psicologia: Reflexão e Crítica, 16(1), 109-116.

Rios, E. R. C. (2006). Intervenção por meio do ensino em estratégias de aprendizagem: contribuições para a produção de textos. Campinas, SP: [s.n.].

Rogers, R. J. (2010). Incorporating metacognitive strategy training in ESP writing instruction: english for lawyers. English Language Teaching, 3(4) pp. 3 -9

Simão,A. M. V. (2005). Estratégias de aprendizageme aconselhamento educacional. Em G. L. Miranda, S. Bahia (Orgs.), Psicologia da educação: Temas de desenvolvimento, aprendizagem e ensino (pp. 263-287). Lisboa: Relógio d’água. 
Sisto, F. F., Boruchovitch, E., Fini, L. D. T., Brenelli, R. P., \& Martinelli, S. C. (2001). Dificuldades de aprendizagem no contexto psicopedagógico (pp. 40-56). Petrópolis, RJ: Vozes.
Woolfolk, A. (2000). Psicologia da educação. Porto Alegre: ARTMED.

Recebido em: 25/05/2012

Reformulado em: 13/12/2012

$15 / 04 / 2013$

Aprovado em: 01/08/2013

\section{Sobre as autoras}

Andrea Regina Teixeira (andrearteixeira@yahoo.com.br)

Prefeitura Municipal de Cambé - PR, Especialista em Psicopedagogia

Paula Mariza Zedu Alliprandini (paulaalliprandini@uel.br)

Universidade Estadual de Londrina - UEL,Pós-doutora em Psicologia

Rod. Celso Garcia Cid - PR 445 - Km 380 - Campus Universitário, Cep 86051-980 - Londrina - PR 